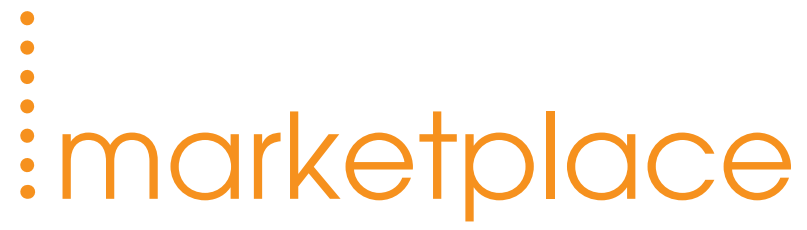

\section{Distinctive signs}

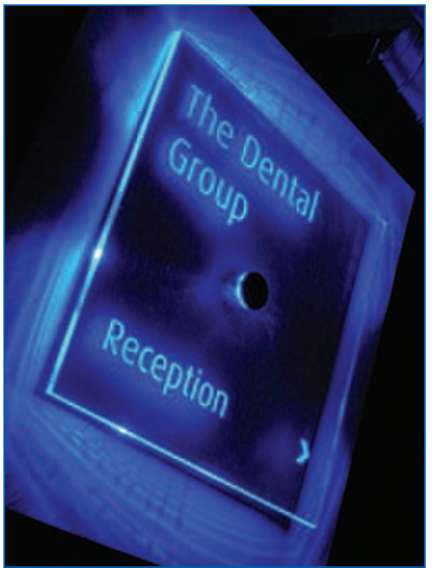

Now you can equip your practice with an attractive signage system that can help to navigate your patients within your practice for less. As part of its Practice Interiors range, Admor has launched a stylish new acrylic sign, offering a contemporary edge to today's dental practices.

Made from $8 \mathrm{~mm}$ acrylic with satin stainless steel fixings, the new acrylic signs offer a low cost alternative to the toughened glass sign also available from Admor. Other signage solutions available include the Stealth Range, the Interior Illuminated Reception Sign, and the Desk Sign.

All Admor signs are wipe clean, to ensure your practice reflects its great image and keeping them looking new every day. For further information call Admor on 01243553078 or visit www.admor.co.uk.

\section{Managing the practice efficiently}

There are eight critical management areas all dental practices must address: staff records, stock control, purchase ledger, payroll, nominal ledger, petty cash, bank and reports. How do you address yours?

Designed to help run the financial and business side of your practice, Kodak Back-Office Software from PracticeWorks is a new range of software and services. Back-Office Reports provides the practice with a full set of key performance indicators; these are reports that demonstrate the financial performance of the practice.

Everything from chair occupancy to the number of referrals to the hygienist and the conversion rate from one scheme to another are included in Reports. The results can be displayed in a number of ways and a summary given in order to highlight areas of the business that require attention. For additional information or to arrange a free demonstration call 08001699692.

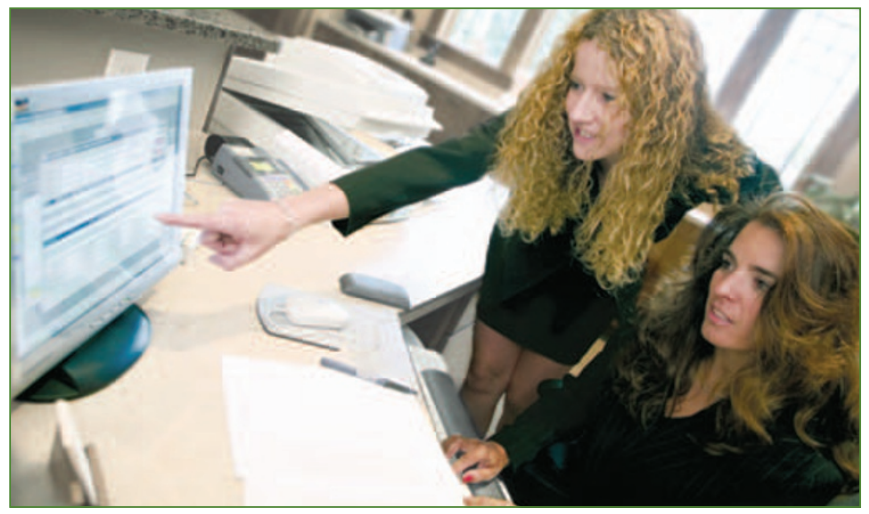

Healing of periodontal wounds

Chlo-Site from Oraldent is the new, non-surgical option for the most efficient healing of periodontal wounds and related problems. Composed of an innovative type of xanthan gel - a hugely advantageous vehicle for clinical applications, Chlo-Site is the only gel where the accessory action of chlorhexidine is capable of maintaining the gel free of contamination for at least 15 days.

Thanks to the muco-adhesive properties of the xanthan, Chlosite adheres to the mucosal tissues acting as a sterile barrier that physically impedes the re-colonisation of bacteria.

Chlorhexidine is present in the gel at a concentration of $1.5 \%$, of which $0.5 \%$ is in the form of a fast releasing digluconate and the remaining $1 \%$ is in the form of a slow releasing dihydrochloride to maintain the microbiological integrity of the xanthan gum.

Supplied in ready to use disposable syringes, Chlo-Site is easily applied into the deepest portion of the periodontal pocket with the specifically designed rounded tip needle to minimise trauma to the tissues. Chlo-site is effective as an adjunctive in the management of periodontal and peri-implant pockets and unlike other topical treatments, will not induce bacterial resistance. For further information on Chlo-Site from Oraldent, telephone 01480862080.

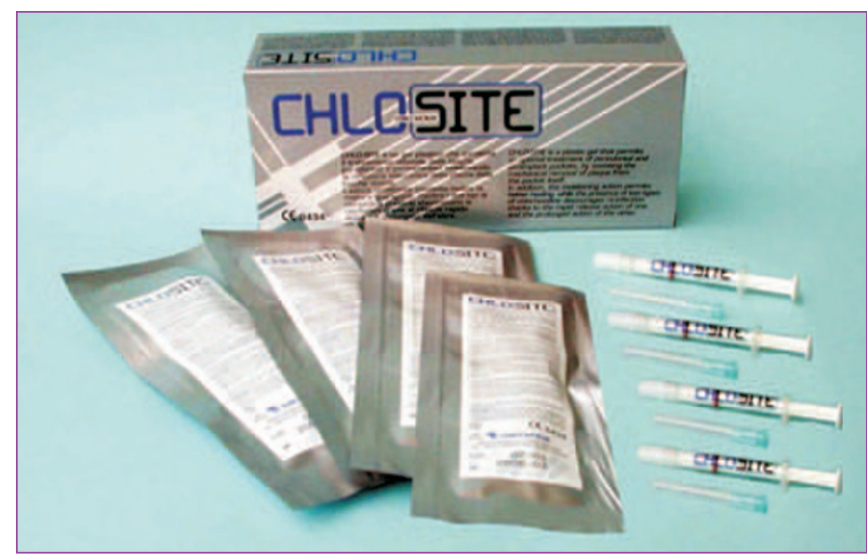

\section{Fast, efficient root canal procedure}

Cavitron has added PEC compatible inserts to its range of products. The PEC insert is available in $25 \mathrm{kHz}$ and $30 \mathrm{kHz}$ providing a fast, efficient, and ergonomic method to prepare

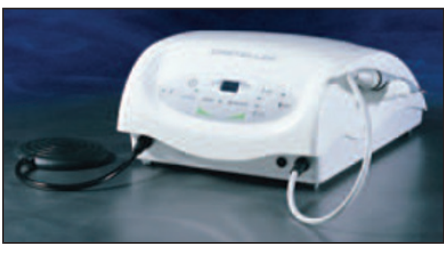
root canals under simultaneous irrigation.

A special offer is currently on for the PEC insert. Buy two Cavitron PEC Inserts (25 k or $30 \mathrm{k}$ ) and receive one standard insert (not PEC or SofTip implant insert) free. Just send a copy of the invoice showing your purchase of two PEC inserts on the same invoice to fax number 01932858970 . To find out more call the Dentsply Preventive team on 01932853422. 